\title{
Treatment strategy for hydatid cysts with multiorgan involvement/localization
}

\author{
Ayşen Taslak Şengüla, Yasemin Bilgin Büyükkarabacak ${ }^{a *}$, Tülin Durgun Yetimº ${ }^{\mathrm{b}}$, Selçuk Gürz ${ }^{\mathrm{a}}$, M. Kemal Demirağ ${ }^{\mathrm{c}}$, \\ Ahmet Başoglu ${ }^{a}$
}

${ }^{a}$ Department of Thoracic Surgery, Medical Faculty, Ondokuz Mayıs University, Samsun, Turkey

${ }^{b}$ Department of Thoracic Surgery, Medical Faculty, Mustafa Kemal University, Hatay, Turkey

c Department of Cardiovascular Surgery, Medical Faculty, Ondokuz Mayls University, Samsun, Turkey

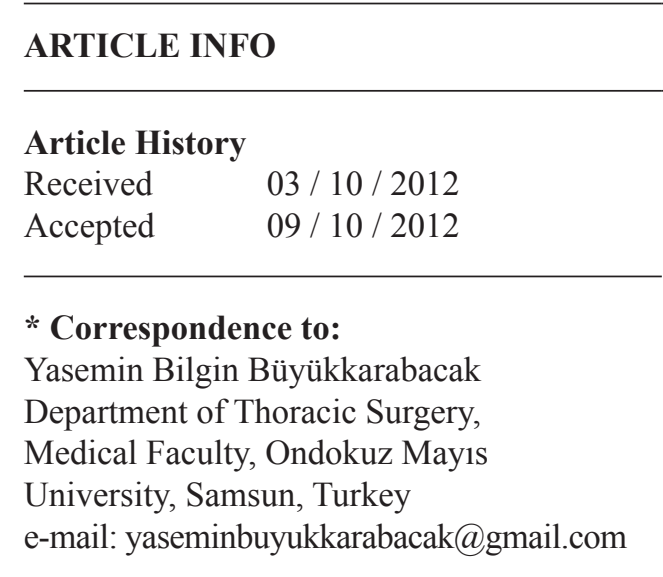

\section{Keywords:}

Hydatid disease

Multiorgan

Lung

Rupture

\section{ABSTRACT}

Hydatid cyst is a parasitic disease commonly observed in developing countries. In this study, 24 patients treated for multiorgan hydatid cyst disease in our clinic between 2001 and 2011 were retrospectively evaluated. Twenty patients had hydatid cysts in lungs and liver; one had cysts in heart, lungs, and liver; one had cysts in heart and lungs; and one had cysts on left diaphragm and liver. Twenty-one patients underwent posterolateral thoracotomy. In two patients, exploration was performed via median sternotomy. During thoracotomy, five cysts located in the right lung and liver were intervened with phrenotomy. Eighteen cysts were excised by using cystotomy plus capitonnage, four by cystotomy plus pericystectomy plus capitonnage, and two by enucleation. Five of the cases were ruptured hydatid cysts. Four of these patients had received $10 \mathrm{mg} / \mathrm{kg} / \mathrm{day}$ albendazole treatment previously due to hydatid cyst of liver. The mean hospital stay was 17 days for ruptured cysts and 7 days for non-ruptured cysts. Preoperative medical treatment in patients with multiorgan hydatid cyst causes pulmonary cyst rupture, and eventually leads to morbidity. So, it is advisable that before starting medical treatment, the lungs should be screened for hydatid cysts.

J. Exp. Clin. Med., 2013; 30:5-9

\section{Introduction}

Hydatid cyst is a parasitic disease commonly observed in developing countries, where agriculture and animal breeding are widespread, and preventive medicine is not sufficient. Its incidence in Turkey is 2 in 100,000 people (Tatar et al., 2003).

Hydatid cysts are caused by Echinococcus granulosus. Although the adult form of the parasite develops in the small intestine of main hosts carnivores such as dogs, wolves, and jackals. The larvae of the parasite settle in different organs of intermediate host herbivores such as cattle, sheep or goats, and humans and cause unilocular cystic Echinococcosis. When ingested by humans, the larval form of the parasite is broken down in the stomach, and the released embryo reaches the liver through the portal system. The disease is observed mostly in the liver (60\%), which has a rich capillary network. Embryos that have passed the liver arrive in the right side of the heart via hepatic veins and the vena cava, ultimately reaching the pulmonary capillaries, where they embed themselves and cause the disease in the lungs (30\%). Embryos that have entered the systemic circulation and cause the disease in other organs (10\%) (Yüksel ve Kalaycı, 2001; Kılıç et al., 2010).

\section{Materials and methods}

Eighty patients treated and followed in our clinic for hydatid cyst between 2001 and 2011 were retrospectively studied. All of the patients were examined with chest X-Ray, computed tomography and ultrasonography. While the localizations of hydatid cysts of lung and liver were determined by using computed tomography (CT) and ultrasound (USG), for cardiac hydatid cysts, echocardiography and magnetic resonance imaging MRI were used. Twenty-four patients with multiorgan hydatid cysts were studied for the symptoms, localizations of cysts, complications and results of medical and surgical treatment.

\section{Results}

Of the patients, 12 were female and 12 were male. The mean age was 35 (13-76) years. The most common symptoms were 


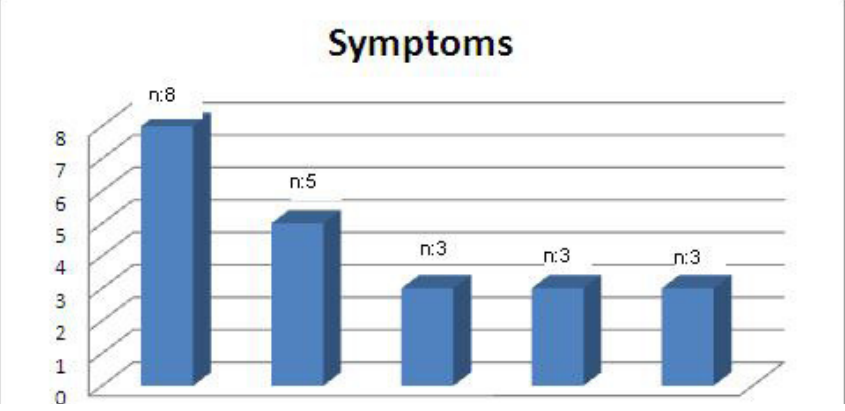

Fig. 1. Symptoms of patients

cough, chest pain, respiratory distress, hemoptysis, and backache (Fig. 1).

Twenty-one patients had hydatid cysts in lungs and liver; one of them had cysts in heart, lungs, and liver; one patient had cysts in heart and liver; and one had a left diaphragmatic cyst and a liver cyst (Fig. 2a,b, Fig. 3a,b). Echocardiography revealed an image suggesting a $5 \mathrm{~cm}$ hydatid cyst lateral to the left ventricle at the level of papillary muscle in the one of the patients with cardiac hydatid cyst and an image suggesting a $3 \mathrm{~cm}$ hydatid cyst on the left atrium wall in the other patient. Electrocardiographs of both patients were normal.

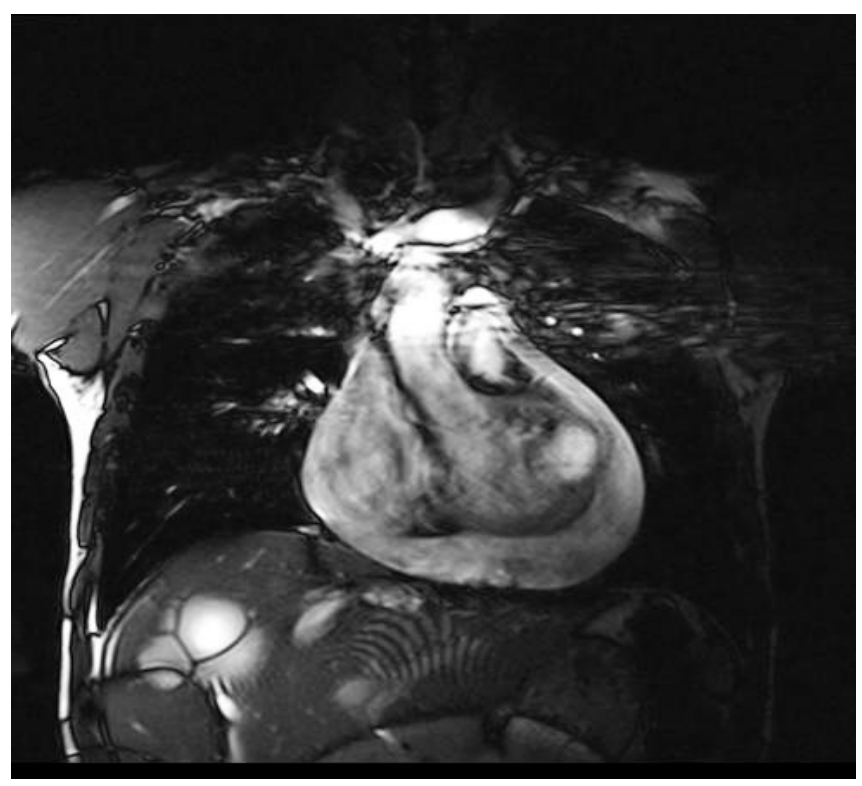

Fig. 2a. Heart and liver cysts

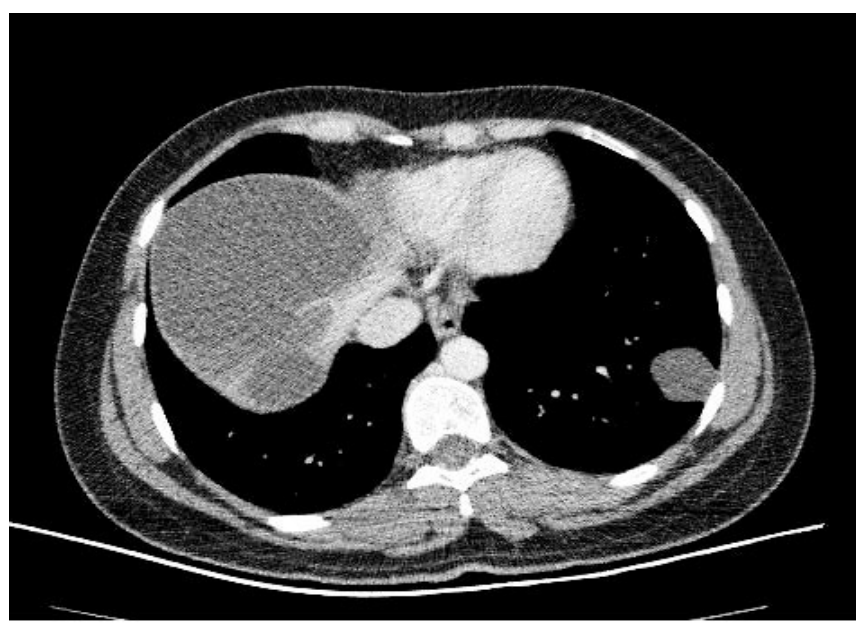

Fig. 2b. Lung and liver cysts

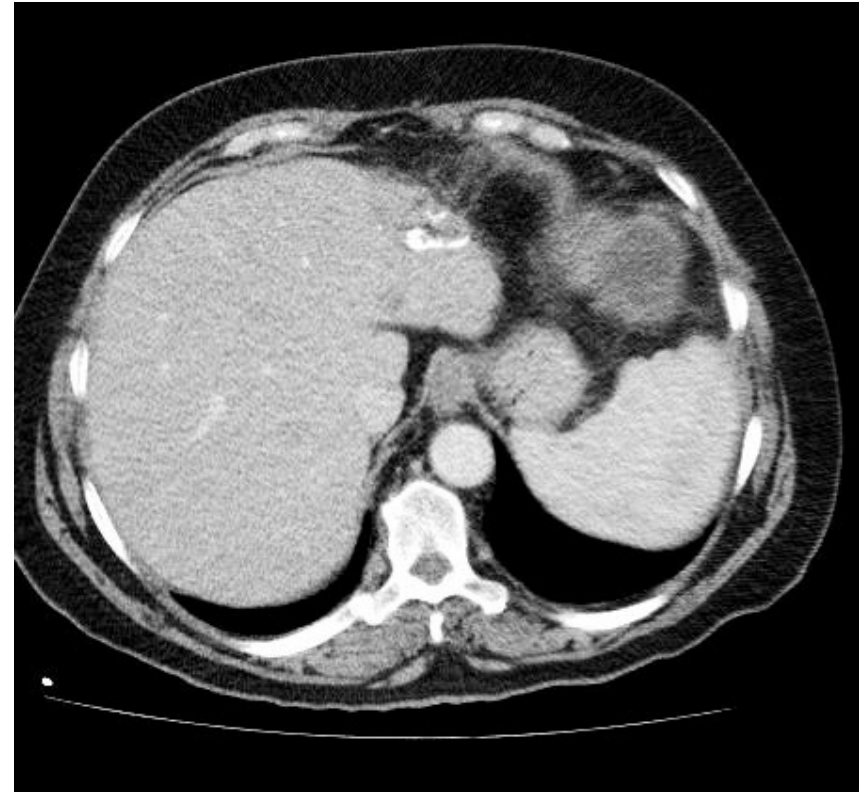

Fig. 3a. Liver and left diaphragmatic cysts

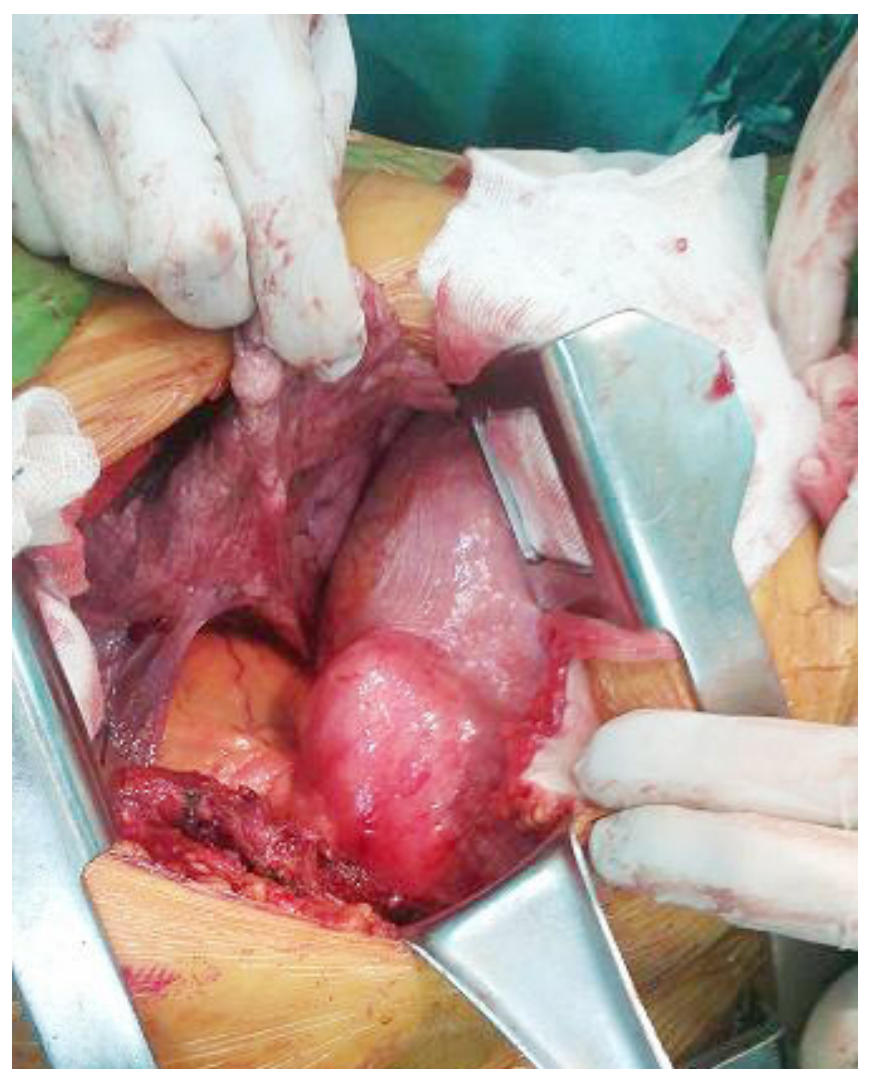

Fig. 3b. Operative image of left diaphragmatic cyst

Twenty-one patients underwent posterolateral thoracotomy. In two patients, exploration was performed via median sternotomy. During thoracotomy, phrenotomy was performed for five cysts located in the right lung and the liver. Seventeen patients with hydatid cyst of liver underwent laparotomy in a later session. Eighteen cysts were excised by using cystotomy plus capitonnage, four by cystotomy plus pericystectomy plus capitonnage, and two by enucleation. The methods performed in our study were enucleation for cysts smaller than $5 \mathrm{~cm}$, and cystotomy and capitonnage for cysts larger than $5 \mathrm{~cm}$, as well as partial pericystectomy, when necessary. No parenchymal resections were performed. In patients with cardiac hydatid cyst, the cysts which were invasive to the myocardium were 
reached under cardiopulmonary by-pass and were excised together with the cyst wall.

Surgical specimens were sent for pathological assessment, and diagnosis of cyst hydatid was also confirmed by pathological examination in all patients.

In 18 patients, the cysts were not ruptured; however, in five patients, ruptured cysts were detected. These five patients, who presented with ruptured pulmonary hydatid cysts, also had hydatid cysts of liver. Four of these patients were first diagnosed with the hydatid cyst of liver and received 10 $\mathrm{mg} / \mathrm{kg} /$ day albendazole treatment for 5-15 days, then they consulted with our clinic for the lung cyst rupture. In one patient, temperature, chest pain, and respiratory distress were marked. Another patient who presented with sepsis and respiratory distress underwent thoracotomy, and drainage and decortication was performed. This patient was intubated due to respiratory failure, remained in the intensive care unit for 25 days postoperatively, and was discharged on the 40th day. Another patient who was operated due to a ruptured hydatid cyst after the medical treatment developed prolonged air leak postoperatively. This patient underwent rethoracotomy due to a recollapsed lung in the second postoperative month.

The mean hospital stay was 9.3 days in all patients. The duration for patients operated for nonruptured cysts was seven days, however, it was 17 days for the patients with ruptured cysts, and they also received broad-spectrum antibiotic therapy during their hospital stay.

Two patients developed pneumothorax postoperatively, which healed spontaneously. In two patients, pneumonia and prolonged air leak were observed. One of the patients with prolonged air leak underwent rethoracotomy due to recollapsed lung in the second postoperative month. All patients received $10 \mathrm{mg} / \mathrm{kg} /$ day albendazol treatment postoperatively. With 1 week break after every 3 weeks, the treatment lasted up to 3 months in patients with nonruptured cysts and up to 6 months in patients with ruptured cysts. During treatment, an increase in transaminases was detected in 2 patients, but it improved spontaneously when the treatment was paused. The patients were followed 3 years in the mean. In the study, no mortality occurred, and no recurrence was observed.

\section{Discussion}

Hydatid disease is still an endemic infectious disease in the Middle East, Australia, New Zealand, South America and Mediterranean countries including Turkey. Its incidence in Turkey is 2 in 100,000 people while it is 5-10 in 100,000 in the world (Tatar et al., 2003).

In primary echinococcosis, larval cysts may develop in any organ. An epidemiological study collected 6.076 surgical interventions for cystic echinococcosis between 1988 and 1992 (Hsairi et al., 1995). It showed that there was liver involvement in $55 \%$ of the cases, and it was followed by lung with $40 \%$, spleen with $1.8 \%$, kidney with $1.4 \%$, bone with $0.1 \%$, heart with $0.2-2 \%$, and the other sites with $1.7 \%$ (Dziri et al., 2009; Koubâa et al., 2012).

Most patients have single-organ involvement and a solitary cyst $(80 \%)$. Multiorgan cyst hydatid disease was rarely seen. Multiple associated locations were observed in $25 \%$ of cases (Dziri et al.,2009). Cysts in liver and lungs usually accompany more than other localizations (8.8-36.5\%) (Athanassiadi et al., 1998; Petrov et al., 2001). There is not suffi- cient data on multiorgan hydatid cysts in the literature, except for those located in the lungs or liver. (Bouckaert et al., 2000) stated that $20-30 \%$ of patients with echinococcus granulosus have multi-organ involvement, with the liver always being involved.

In this study, of the 80 patients treated in our clinic for hydatid cysts over the last ten years, $85-90 \%$ had single organ involvement, and $70 \%$ had only one cyst, and 24 multiorgan hydatid cyst cases were observed. Consistent with the literature, the most common combination in our series was lung and liver combination.

Cardiac hydatid cysts are not common. They make up $0.2-2 \%$ of all cyst cases (Díaz-Menéndez et al., 2012). It is transported to the heart through coronary arteries. The most common localization is the myocard, specifically the left ventricular wall (50-60\%) and interventricular septum (\%10-20) Right or left atrium may be also involved. (Engin et al., 2000; Koubâa et al., 2012). Echocardiography is the most reliable method in diagnosing and in determining the localization of the cardiac hydatid cysts. When cardiac cysts rupture and enter the circulatory system, the severe anaphylactic reaction can lead to ischemic syndrome with the compression on coronary arteries or to arrhythmias, heart failure and pulmonary embolisms with the compression on atrioventricular branches. So, they should urgently be treated. (Miralles et al., 1994; Keles et al., 2000). In the guidebook of World Health Organization, surgery is recommended as the basic treatment for cardiac hydatid cysts. Medical therapy should be given to elderly patients with small, atotal calcific, asymptomatic, negative hydatid serology. A long-term medical therapy is recommended only for inoperable patients or patients who have undergone incomplete resection. Patients who have undergone complete resection can receive medical therapy only during the 2-year postoperative follow-up period (WHO Informal Working Group of Echinococcosis. 1996).

Multiorgan hydatid cysts are complex and destructive cases. Furthermore, there is no standard treatment strategy (Guven et al., 2004). The treatment strategy should be determined depending on the location and size of the cysts, and whether the cysts are ruptured or not. When hydatid cyst of the right lung accompanies a second cyst on the liver dome, right thoracopherenotomy may provide a single intervention to treat both cysts. When hydatid cyst of liver does not allow transdiaphragmatic intervention, thoracotomy should be the first choice in treating pulmonary hydatid cyst, because positive pressure ventilation under general anesthesia may cause pulmonary cyst rupture (Sengul and Basoglu, 2010). In multiorgan hydatid cysts, if there is a cardiac cyst, the surgical priority should be given to the heart due to the mortal complications it may cause. If there is also an accompanying pulmonary hydatid cyst, pulmonary hydatid cyst intervention should be done with median sternotomy at appropriate localizations in the same session.

As well as peritoneal hydatid cysts, the World Health Organization suggests chemotherapy for inoperable primary hydatid cysts of the liver and lung in patients with multiple cysts in two or more organs. Another important indication of chemotherapy is to prevent secondary hydatid cysts (WHO Informal Working Group 1996; Harlaftis et al., 2005). Benzimidazoles (albendazole and mebendazole) are the most commonly used agents for this purpose. These pharmaceuticals 
inhibit the accumulation of tubulin in microtubules and disrupt glucose absorption through the cyst wall. Consequently, all the glucose reserves are depleted, and cell death occurs. Albendazole is preferred to mebendazole, because it provides a more effective treatment with lower doses and shorter treatment periods, and it has fewer side effects (Sengul and Basoglu 2010). Furthermore, compared to mebendazole, albendazole is absorbed in higher doses through gastrointestinal system (GIS) and reaches to higher plasma concentrations (Bozbuga et al., 2003).

In our clinic, medical treatment is used not only for the cases that cannot be treated surgically but also in preventing recurrence. The postoperative treatment duration is three months in nonruptured cysts, and 6 months in ruptured cysts. Albendazole is preferred when treating hydatid cysts of the liver, and successful results have been reported (Davis et al., 1986; Balik et al., 1999; Kurkcuoglu et al., 2002) reported partial or complete success rates as $14 \%$ in the mebendazole group and $30 \%$ in the albendazole group. There are studies reporting that medical treatment used pre- and post-operatively decreased the recurrence risk (Morris et al., 1985; Dhaliwal and Kalkat, 1997).

Burgos et al. (1999) recommend the use of albendazole preoperatively for 7-10 days and postoperatively one month in intact cysts and 3-6 months in ruptured cysts. In our clinic, we give albendazole postoperatively up to 3 months for nonruptured cysts and up to 6 months for ruptured cysts. No preoperative medical treatment is given in our clinic due to the risk of rupture.

However, in pulmonary hydatid cysts, medical treatment alone weakens the cyst wall and causes rupture (Koppen et al.,
2003). Ruptured pulmonary hydatid cysts can lead to serious complications. The antigens released stimulate the mast cells, and histamine secretion increases. Although it is rare, allergic reactions or life-threatening anaphylaxis may develop (Kuzucu et al., 2004; Yüceyar et al., 2004). Wen and Yang (1997) reported a $77.3 \%$ incidence of ruptured cyst in 21 patients they treated with albendazole. Particularly in pulmonary cyst ruptures, the contamination of pleural space increases mortality and morbidity (Koppen et al., 2003). In our clinic, four of the patients with ruptured cysts due to preoperative medical treatment developed serious postoperative complications. Duration of hospital stay, postoperative antibiotic therapy and chest tube drainage took more time in these patients than the other patients.

In conclusion, the main treatment for pulmonary hydatid cysts is surgery. If there is an accompanying pulmonary and/ or cardiac cyst in a multilocal hydatid cyst case, the surgical treatment priority should be on these cysts due to the mortal complications they may cause. Medical treatment in pulmonary hydatid cysts is recommended only if the cyst is inoperable due to secondary pathologies, or only if the cysts are too many to be resected. Preoperative medical treatment in patients with multiorgan hydatid cysts causes perforation of pulmonary cysts, and consequently leads to morbidity. Therefore, before starting medical treatment, the lungs should be screened for hydatid cysts, and patients with hydatid cysts should primarily be evaluated for surgery. Medical treatment should be considered after the surgery to prevent recurrence of the pulmonary hydatid cyst or to treat cysts located in other organs.

\section{REFERENCES}

Athanassiadi, K., Kalavrouziotis, G., Loutsidis, A., Bellenis, I., Exarchos, N., 1998. Surgical treatment of echinococcosis by a transthoracic approach: A review of 85 cases. Eur. J. Cardiothorac. Surg. 14, 134-140.

Balik, A.A., Basoglu, M., Celebi, F., Oren, D., Polat, K.Y., Atamanalp, S.S., Akçay, M.N., 1999. Surgical treatment of hydatid disease of the liver: Review of 304 cases. Arch. Surg. 134, 166-169.

Bouckaert, M.M., Raubenheimer, E.J., Jacobs, F.J., 2000. Maxillofacial hydatid cysts. Oral. Surg. Oral. Med. O. 89, 338-342.

Bozbuga, N., Erentug, V., Akinci, E., Yakut, C., 2003. Is surgical therapy the only treatment of choice for cardiac echinococcossis with multiple organ involvement? Interac. Cardiovasc. Thorac. Surg. 2, 367-368.

Burgos, R., Varela, A., Castedo, E., Roda, J., Montero, C.G., Serrano, S., Téllez, G., Ugarte, J., 1999. Pulmonary hydatidosis: Surgical treatment and follow-up of 240 cases. Eur. J. Cardiothorac. Surg. 16, 628-634.

Davis, A., Pawlowski, Z.S., Dixon, H., 1986. Multicentre clinical trials of benzimidazole carbamates in human echinococcosis. Bull. WHO. 64, 383-388.

Dhaliwal, R.S, Kalkat, M.S., 1997. One-stage surgical procedure for bilateral lung and liver hydatid cysts. Ann. Thorac. Surg. 64, 338-341.

Diaz-Menendez, M., Pérez-Molina, J.A., Norman, F.F., Pérez-Ayala, A., Monge-Maillo, B., Fuertes, P.Z., López-Vélez, R., 2012. Management and outcome of cardiac and endovascular cystic echinococcosis. PLOS. Negl. Trop. 6, 1437.

Dziri, C., Haouet, K., Fingerhut, A., Zaouche, A., 2009. Management of Cystic echinococcosis Complications and Dissemination: Where is the Evidence? World J. Surg. 33, 1266-1273.

Engin, B., Acunas, B., Rozanes, I., Acunas, G., 2000. Hydatid disease with unusual localization. Eur. Radiol. 10, 1904-1912.

Guven, A., Sokmen, G., Yuksel, M., Kokoglu, O.F., Koksal, N., Cetinkaya, A., 2004. A case of asymptomatic cardiopericardial hydatid cyst. Jpn. Heart J. 45, 541-545.

Harlaftis, N.N., Aletras, H.A., Symbas, P.N., 2005. Hydatid Disease of the Lung. In Shields TW: General Thoracic Surgery. Lippincott Williams Wilkins, Philadelphia. 1298-1308.

Hsairi, M., Chahed, M.K., Bchir, A., Dammak, J., Kilani, T., Kebir, A., Kamel, N., Dziri, C., Sidhom, M., 1995. Incidence chirurgicale del'hydatidose en Tunisie Tunisie Chirurgicale. 4, 20-26.

Keles, C., Sismanoglu, M., Bozbuga, N., Erdogan, H.B., Akinci, E., Ipek, G.,Yakut, C., 2000. A cardiac hydatid cyst involving the basal interventricularseptum causing biventricular outflow tract obstruction. Thorac. Cardiovasc. Surg. 48, 377-379.

Kılıç, Ö., Camcıŏlu, Y., Akçakaya, N., Çokuğraş, H., Ataseven, F., Dashtir, ve ark., 2010. Nadir primer serebral yerleşimli hidatik kist olgusu. Çocuk Enf. Derg. 4, 117-119.

Koppen, S., Wejda, B., Dormann, A., Seesko, H., Huchzermeyer, H., Junghanss, T., 2003. Anaphylactic shock caused by rupture of an echinococcal cyst in a 25-year-old asylum seeker from Georgia. Dtsch. Med. Wochenschr. 128, 663-666.

Koubâa, M., Lahiani, D., Abid, L., Mâaloul, I., Kahla, S.B., Bradii, M., Marrakchi, C., Hammami, B., Mnif, Z., Mnif, J., Kammoun, S., Jemâa, MB., 2012. Can albendazole be the only treatment for cardiac echinococcosis with multiple organ involvement? Int. J. Cardiol. 161, 58-60. 
Kurkcuoglu, İ.C., Eroglu, A., Karaoglanoglu, N., Polat, P., 2002. Complications of albendazole treatment in hydatid disease of lung. Eur. J. Cardio-Thorac. Surg. 22, 649-650.

Kuzucu, A., Soysal, Ö., Özgel, M., Yoloğlu, S., 2004. Complicated hydatid cysts of the lung: Clinical and therapeutic issues. Ann. Thorac. Surg. $77,1200-1204$.

Miralles, A., Bracamonte, L., Pavie, A., Bors, V., Rabago, G., Gandjbakhch, I,, Cabrol, C., 1994. Cardiac echinococcosis. Surgical treatment and results. J. Thorac. Cardiov. Surg. 107, 184-190.

Morris, D.L., Dykes, P.W., Marriner, S., Bogan, J., Burrows, F., Skeene-Smith, H., Clarkson, M.J., 1985. Albendazole: Objective evidence of response in human hydatid disease. JAMA. 253, 2053-2057.

Petrov, D.B., Terzinacheva, P.P., Djambazov, V.I., Plochev, M.P., Goranov, E.P., Minchev, T.R., Petrov, P.V., Minchev, T.R., 2001. Surgical treatment of bilateral hydatid disease of the lung. Eur. J. Cardiothorac. Surg. 19, 918-923.

Sengul, A.T., Basoglu, A., 2010. Pulmonary Hydatidosis. In: Erzurumlu K editor. Human Echinococcosis. 1.Edition. Avrupa Tip Kitapç11ık Ltd. Şti İstanbul-Turkey. pp: 99-110.

Tatar, D., Güneş, E., Berktaş, Ö., Güneş, P., 2003. Akciğer kist hidatiği tanılı çocuk olgularımız. Akciğer Arşivi. 4, 31-35.

Wen, H., Yang, 1997. WG: Public health importance of cystic echinococcosis in China. Acta Trop. 67, 133-145.

WHO Informal Working Group of Echinococcosis. World Health Organization, Guidelines for treatment of cystic and alveolar echinococcosis in humans. B. World Health Organ. 1996. 74, 231-242.

Yüceyar, L., Demirok, M., Özdilmaç, İ., Beşirli, K., Aykaç, B., 2004. Akciğer kist hidatiği nedeniyle torakotomi uygulanan hastada anafilaksi. Solunum. 6, 235-238.

Yüksel, M., Kalayc1, G., 2001. Akciğer kist hidatiğinin cerrahi tedavisi İn: Yüksel, M. Kalayc1, G. Göğüs Cerrahisi 1.Edition Bilmedya grup İstanbul 46, 647-658. 